\title{
What are the motivations for joining medical education related "World Café" workshop?
}

\author{
Cheng, Y.C. ${ }^{1}$, Chang, L.C. ${ }^{1}$, Chen, C.H. ${ }^{1}$, Hsu, C.Y. ${ }^{1}$, Tu, H.P. ${ }^{2}$, Wang, L.C. ${ }^{2}$ \\ ${ }^{1}$ Ditmanson Medical Foundation, Chia-Yi Christian Hospital, Taiwan \\ ${ }^{2}$ The Medical Education and Research Center, Tainan Sin-Lau Hospital, the Presbyterian Church in \\ Taiwan, Tainan, Taiwan
}

\section{Background:}

"World Café" is used widely in medical education. However, motivation of joining by qualitative research is rare. Here, we investigate the motivation for joining medical education related "World Café" workshop by qualitative analysis.

\section{Method:}

The workshop applying by "World Café" model was performed on October 20, 2020. There were 24 colleagues ( 23 women and 1 man) to join the workshop. Four topics with medical education related problems were discussed. It took 3 and half hours. After the workshop, a focus group interview was made. The verbatim transcripts of interview were studied by qualitative analysis to search the motivation.

\section{Results}

Six participants ( 5 women and 1 man) were agreed to be interviewed after the workshop. The interview lasted 40 minutes. The qualitative analysis revealed that: 1 . Operational needs: the participants with "World Café" joining experience mentioned that they agreed this model and will adopt this model to solve clinic problems in the future. 2. Invitation by experienced colleagues: the participants without experience described that they were strongly recommend and encouraged by experienced colleagues. 3. Attraction by the name: both were attracted by the name of "World Café" which indicates relaxation.

\section{Conclusion:}

Operational needs and invitation by experienced colleagues are the motivations for experienced and inexperienced participants. However, both consider that the name of "Café" is attractive and it stands for relaxation.

Key words: World Café, motivation, medical education 